\title{
Sex Differences in the Relation of Body Composition to Cardiovascular Parameters and Functions in Korean Adolescents: A School-Based Study
}

\author{
Young-Hwan Song ${ }^{a}$ Hae Soon Kim ${ }^{b}$ Hae Sook Park ${ }^{c}$ Jo Won Jung ${ }^{f}$ \\ Nam Su Kim ${ }^{d}$ Chung Il Noh ${ }^{e}$ Young Mi Hong ${ }^{b}$ \\ aDepartment of Pediatrics, Sanggye Paik Hospital, College of Medicine, Inje University, \\ ${ }^{b}$ Department of Pediatrics, ' Department of Preventive Medicine, School of Medicine, \\ Ewha Womans University, ${ }^{d}$ Department of Pediatrics, School of Medicine, Han Yang \\ University, ${ }^{e}$ Department of Pediatrics, School of Medicine, Seoul National University, Seoul, \\ ${ }^{f}$ Department of Pediatrics, School of Medicine, Ajou University, Suwon, South Korea
}

\section{Key Words}

Adolescent · Body composition · Cardiac output · Blood pressure $\cdot$ Pulse wave velocity

\begin{abstract}
Objective: Obesity in adolescence is associated with increased cardiovascular risk. The patterns of obesity and body composition differ between boys and girls. It is uncertain how body composition correlates with the cardiovascular system and whether such correlations differ by sex in adolescents. Methods: Body composition (fat-free mass (FFM), adipose mass, waist circumference (WC)) and cardiovascular parameters and functions were studied in 676 healthy Korean adolescents aged 12-16 years. Partial correlation and path analyses were done. $\boldsymbol{R e}$ sults: WC correlated with stroke volume (SV) and cardiac output (CO), systolic blood pressure (SBP) and pulse pressure (PP), cardiac diastolic function (ratio of early to late filling velocity (E/A ratio)), and vascular function (pulse wave velocity (PWV)) in boys. Adipose mass was related to SV, CO, SBP, PP, left ventricular mass (LVM), and PWV in girls - and to E/A ratio in both sexes. FFM affected SV, CO, SBP, and PP in both sexes and LVM in boys. Cardiac systolic functions had no relation with any body composition variable in either sex. Conclusion: In adolescence, the interdependence of the cardiovascular system and the body composition differs between sexes. Understanding of those relations is required to control adolescent obesity and prevent adult cardiovascular disease.

(c) 2014 S. Karger GmbH, Freiburg
\end{abstract}


Song et al:: Sex Differences in the Relation of Body Composition to Cardiovascular

Parameters and Functions in Korean Adolescents: A School-Based Study

\section{Introduction}

Studies in youths have found that obesity is associated with cardiovascular disease (CVD) risk factors and strongly predicts CVD in adulthood, suggesting that the pathophysiological processes underlying CVD begin early in life $[1,2]$. Adolescence is a transitional period between childhood and adulthood in which rapid physical growth, sexual maturation, and cardiovascular changes occur. However, little is known about the relative contribution of obesity-related body composition variables to CVD risk factors or about the existence of any sex differences in such relations in adolescents.

Obesity is known to induce an increase in blood flow (stroke volume (SV) and cardiac output (CO)) to achieve an elevated metabolic rate, thereby leading to an increase in hemodynamic load both on the heart and vessels [3]. In obesity, increased blood flow and inadequate vascular resistance are likely to cause hypertension, which is an important CVD risk factor [4]. Hypertension and increased blood flow may lead to left ventricular (LV) hypertrophy in obese persons [5]. This structural change is likely to cause an impairment of ventricular filling, resulting in cardiac diastolic dysfunction. In addition, long-standing pressure and volume overload may cause cardiac systolic dysfunction [6]. Obesity can also result in vascular dysfunction through hypertension and diverse neurohumoral effects.

Studies in adults have suggested that the obesity-associated CVD risk is related primarily to increased adipose tissue mass [7]. Central adiposity seems to be especially deleterious because of the metabolic characteristics of fat stored in the intra-abdominal visceral compartment [8-10]. Being overweight is also associated with increased fat-free mass (FFM), which represents metabolically active tissue [9]. FFM is also known to be correlated with cardiovascular parameters including SV, CO, blood pressure (BP), and LV mass (LVM) [1214].

To evaluate the sex-specific individual effects of body composition variables on the cardiovascular system in adolescents, we examined the relations of FFM, adipose mass, and waist circumference (WC) with cardiovascular parameters (SV, CO, LVM, and BP) and functions (systolic and diastolic function, pulse wave velocity (PWV)), using partial correlation and path analyses.

\section{Material and Methods}

\section{Participants}

This is a school-based, cross-sectional study of adolescents living in Seoul, South Korea. Parental reports of the participants' medical histories indicated that all subjects were apparently healthy and were taking no medications that might influence the results. We excluded subjects with congenital heart disease, significant valvular stenosis, or regurgitation on echocardiographic examination.

All participants and their parents provided written informed consent. The institutional review board of Ewha Womans University Medical School approved this study.

\section{Anthropometry and Blood Pressure}

Body weight was measured with calibrated electronic scales, and height was measured with a stadiometer. WC was measured using a metal anthropometric tape at the midway point between the lowest rib and the iliac crest in a standing position at minimal respiration. BMI was calculated. BP was measured 3 times in the supine position after 10 min of quiet rest, using an automatic oscillometric method (Dinamap Procare 200; GE Medical Systems, Milwaukee, WI, USA).

Body Composition

FFM, adipose mass and the percentage of body fat were estimated by bioelectric impedance analysis (BIA) (InBody 720; Biospace Co., Ltd., Seoul, South Korea), using the equation in the BIA software [15]. 
Song et al.: Sex Differences in the Relation of Body Composition to Cardiovascular

Parameters and Functions in Korean Adolescents: A School-Based Study

\section{Echocardiography}

Echocardiographic evaluations were performed according to the recommendations of the American Society of Echocardiography [16], using phased-array echocardiographs with M-mode, 2-dimensional as well as pulsed and color-flow Doppler capacities (Acuson Sequoia C512; Siemens, Munich, Germany). Echocardiographic images were obtained with the subject in the left partial decubitus position. The LV internal dimensions and septal and posterior wall thickness were measured at the end of the diastole and the end of the systole from M-mode tracings in the parasternal long axis. The diameter of the aortic annulus was measured in the parasternal long-axis view. Doppler transaortic flow was assessed at the center of the aortic annulus in the apical long-axis or 5-chamber view. Doppler transmitral blood flow was measured to determine early (E) and late (A) diastolic peak filling velocity and the E/A ratio. For each participant, a representative value was obtained from the average of 3 measurements.

SV was calculated as the aortic annular cross-sectional area $\times$ the aortic time-velocity integral. CO was derived as SV $\times$ heart rate (HR) [17]. LVM was determined using a validated formula [18]. Ejection fraction was calculated using the biplane Simpson formula [19]. Fractional shortening was calculated using the LV internal dimensions.

Pulse Wave Velocity

Brachial-ankle PWV was measured automatically in the supine position with a volume-plethysmographic apparatus (PWV/ABI; Colin Co., Ltd., Komaki, Japan) [20]. The average of the left and right brachialankle PWVs in each subject was used as the PWV.

\section{Statistical Analyses}

Data are presented as means \pm SD. Because of the known influence of sex on body composition, the analyses were performed separately for boys and girls. We conducted path analyses to investigate the full range of interrelations (total and direct) between body composition variables (FFM, adipose mass, WC) and cardiovascular parameters including SV, CO, HR, systolic BP (SBP), pulse pressure (PP), and LVM [21]. A path diagram was constructed based on previous findings, theoretical rationales, and stepwise multiple regression analyses with the criterion of $\mathrm{p}<0.05$ for a variable to enter the model. Age-adjusted partial correlations between body composition and cardiovascular functions (systolic and diastolic functions and PWV) were analyzed. Standardized estimates (path coefficients) in path analyses and correlation coefficients in partial correlation analyses were used to estimate the strength of correlations between dependent and independent variables. Two-tailed $\mathrm{p}$ values $<0.05$ indicated statistical significance.

Identification of a subject as being overweight (BMI > 85th percentile) was assessed based on age- and sexspecific BMI reference charts for Korean adolescents [22]. We analyzed the associations of being overweight with cardiovascular parameters and functions by using Student's t test. The level of significance was set at $\mathrm{p}<0.05$.

\section{Results}

Participants

Complete sets of data were obtained for 676 adolescents: 397 boys and 279 girls. The ages of the participating boys and girls had similar means and ranged from 12 to 16 years. As shown in table 1, adipose mass and percentage of body fat were greater in girls, whereas all other measures of body size, composition, and BMI were greater in boys. Cardiovascular parameters, including SV, CO, LVM, SBP and PP, were higher in boys. Boys and girls showed similarities in HR, systolic and diastolic function, and PWV.

\section{Correlations of Body Composition with Cardiovascular Parameters}

We analyzed the partial correlations of body composition variables (FFM, adipose mass, WC) with cardiovascular parameters (SV, CO, SBP, PP, LVM) adjusted for age (table 2). SV and CO correlated with FFM, WC and adipose mass in both boys and girls. SBP and PP positively correlated with FFM, WC, and adipose mass in both sexes. Positive correlations of LVM with FFM, WC, and adipose mass were also observed in boys and girls. 
Table 1. Characteristics of subjects
Table 2. Univariate correlates of body composition with cardiovascular parameters adjusted for age in boys and girls***

\begin{tabular}{l|l}
\hline DOI: $10.1159 / 000362345$ & $\begin{array}{l}\text { C } 2014 \text { S. Karger GmbH, Freiburg } \\
\text { www.karger.com/ofa }\end{array}$ \\
\hline
\end{tabular}

Song et al.: Sex Differences in the Relation of Body Composition to Cardiovascular Parameters and Functions in Korean Adolescents: A School-Based Study

\begin{tabular}{llll}
\hline & Boys $(\mathrm{n}=397)$ & Girls $(\mathrm{n}=279)$ & $\mathrm{p}$ value \\
\hline Age, years & $13.7 \pm 0.9$ & $13.6 \pm 0.9$ & NS \\
Height, cm & $164.0 \pm 8.1$ & $157.6 \pm 4.9$ & $<0.001$ \\
Weight, kg & $58.6 \pm 12.9$ & $50.6 \pm 7.9$ & $<0.001$ \\
WC, cm & $71.6 \pm 10.0$ & $65.3 \pm 6.1$ & $<0.001$ \\
FFM, kg & $45.8 \pm 7.9$ & $36.2 \pm 3.7$ & $<0.001$ \\
Adipose mass, kg & $12.8 \pm 7.5$ & $14.4 \pm 5.2$ & $<0.001$ \\
BMI, kg/m & $21.6 \pm 3.8$ & $20.3 \pm 2.6$ & $<0.001$ \\
Percent body fat, \% & $20.7 \pm 8.6$ & $27.6 \pm 6.2$ & $<0.001$ \\
SV, ml & $55.5 \pm 12.2$ & $49.5 \pm 10.1$ & $<0.001$ \\
CO, l/min & $4.1 \pm 1.0$ & $3.8 \pm 0.9$ & $<0.001$ \\
HR, beats/min & $75.3 \pm 12.5$ & $77.2 \pm 11.9$ & NS \\
SBP, mm Hg & $116.5 \pm 10.4$ & $109.2 \pm 9.1$ & $<0.001$ \\
PP, mm Hg & $54.6 \pm 6.8$ & $48.4 \pm 6.1$ & $<0.001$ \\
LV mass, g & $119.0 \pm 28.6$ & $106.3 \pm 19.5$ & $<0.001$ \\
Ejection fraction, \% & $67.6 \pm 4.2$ & $66.9 \pm 5.9$ & NS \\
Fractional shortening, \% & $37.3 \pm 3.5$ & $36.9 \pm 4.9$ & NS \\
E velocity, cm/s & $101.2 \pm 15.8$ & $100.5 \pm 14.2$ & NS \\
A velocity, cm/s & $53.3 \pm 11.2$ & $53.0 \pm 10.8$ & NS \\
E/A ratio & $1.98 \pm 0.53$ & $1.97 \pm 0.48$ & NS \\
PWV, m/s & $9.7 \pm 0.9$ & $9.6 \pm 0.9$ & NS \\
\end{tabular}

$\mathrm{WC}=$ Waist circumference; FFM = fat-free mass; $\mathrm{SV}=$ stroke volume; $\mathrm{CO}=$ cardiac output; $\mathrm{HR}=$ heart rate; $\mathrm{SBP}=$ systolic blood pressure; $\mathrm{PP}$ = pulse pressure; $\mathrm{PWV}=$ pulse wave velocity; NS = nonsignificant.

\begin{tabular}{lllllllll}
\hline & \multicolumn{3}{l}{ Boys $(\mathrm{n}=397)$} & & \multicolumn{3}{l}{$\operatorname{Girls}(\mathrm{n}=279)$} \\
\cline { 2 - 4 } \cline { 7 - 8 } & FFM & $\begin{array}{l}\text { adipose } \\
\text { mass }\end{array}$ & WC & & FFM & & $\begin{array}{l}\text { adipose } \\
\text { mass }\end{array}$ & WC \\
\hline SV & 0.433 & 0.335 & 0.361 & & 0.443 & 0.420 & 0.423 \\
CO & 0.374 & 0.350 & 0.385 & & 0.370 & 0.401 & 0.380 \\
SBP & 0.356 & 0.412 & 0.431 & & 0.337 & 0.462 & 0.415 \\
PP & 0.378 & 0.376 & 0.401 & & 0.310 & 0.367 & 0.339 \\
LVM & 0.419 & 0.309 & 0.326 & & 0.445 & 0.595 & 0.552 \\
\hline
\end{tabular}

FFM = Fat-free mass; $\mathrm{WC}=$ waist circumference; $\mathrm{SV}=$ stroke volume; $\mathrm{CO}$ = cardiac output; $\mathrm{SBP}=$ systolic blood pressure; $\mathrm{PP}=$ pulse pressure; LVM = left ventricular mass. ${ }^{* * *} \mathrm{p}<0.001$ in all correlations.

\section{Path Analyses of the Effects of Body Composition on Cardiovascular Parameters}

We used a structural equation model to analyze the complex effects of body composition on cardiovascular parameters by means of path analysis, which allows for the simultaneous conduction of multiple linear regression analyses (fig. 1) [21]. We performed stepwise multiple regression analyses to determine which variables would enter the model with the criterion of $\mathrm{p}<0.05$ before the construction of the path diagram.

The path model exhibited good fit across a number of model fit indices in boys and girls: $\chi^{2}=21.01(\mathrm{df}=17, \mathrm{p}<0.01)$ in boys and $=13.21(\mathrm{df}=16, \mathrm{p}<0.01)$ in girls; probability level $=0.223$ in boys and $=0.658$ in girls; root mean square error of approximation $=0.025$ in boys and $<0.001$ in girls; comparative fit index $=0.998$ in boys and $=1$ in girls (fig. 1 ). 
Fig. 1. Path analysis diagrams of body composition variables, age, and cardiovascular parameters for boys (top; chi-square $=21.01$, $\mathrm{df}=17, \mathrm{p}<0.01$, probability Ievel $=0.223$, root mean square error of approximation $=0.025$, comparative fit index $=0.998$ ) and girls (bottom; chi-square $=13.21$, $\mathrm{df}=16, \mathrm{p}<0.01$, probability Ievel $=0.658$, root mean square error of approximation < 0.001, comparative fit index $=1$ ). The heavily lined boxes indicate the main body composition variables in the correlation with cardiovascular parameters. Numbers indicate the individual relations between the variables of the path diagram in table 3 . The respective estimates (path coefficients) and $\mathrm{p}$ values are presented in table 3 (direct effects) and table 4 (total effects). FFM = Fat-free mass; WC = waist circumference; $\mathrm{SV}=$ stroke volume; $\mathrm{HR}=$ heart rate; $\mathrm{SBP}=$ systolic blood pressure; $\mathrm{PP}=$ pulse pressure; LVM = left ventricular mass.

Song et al.: Sex Differences in the Relation of Body Composition to Cardiovascular

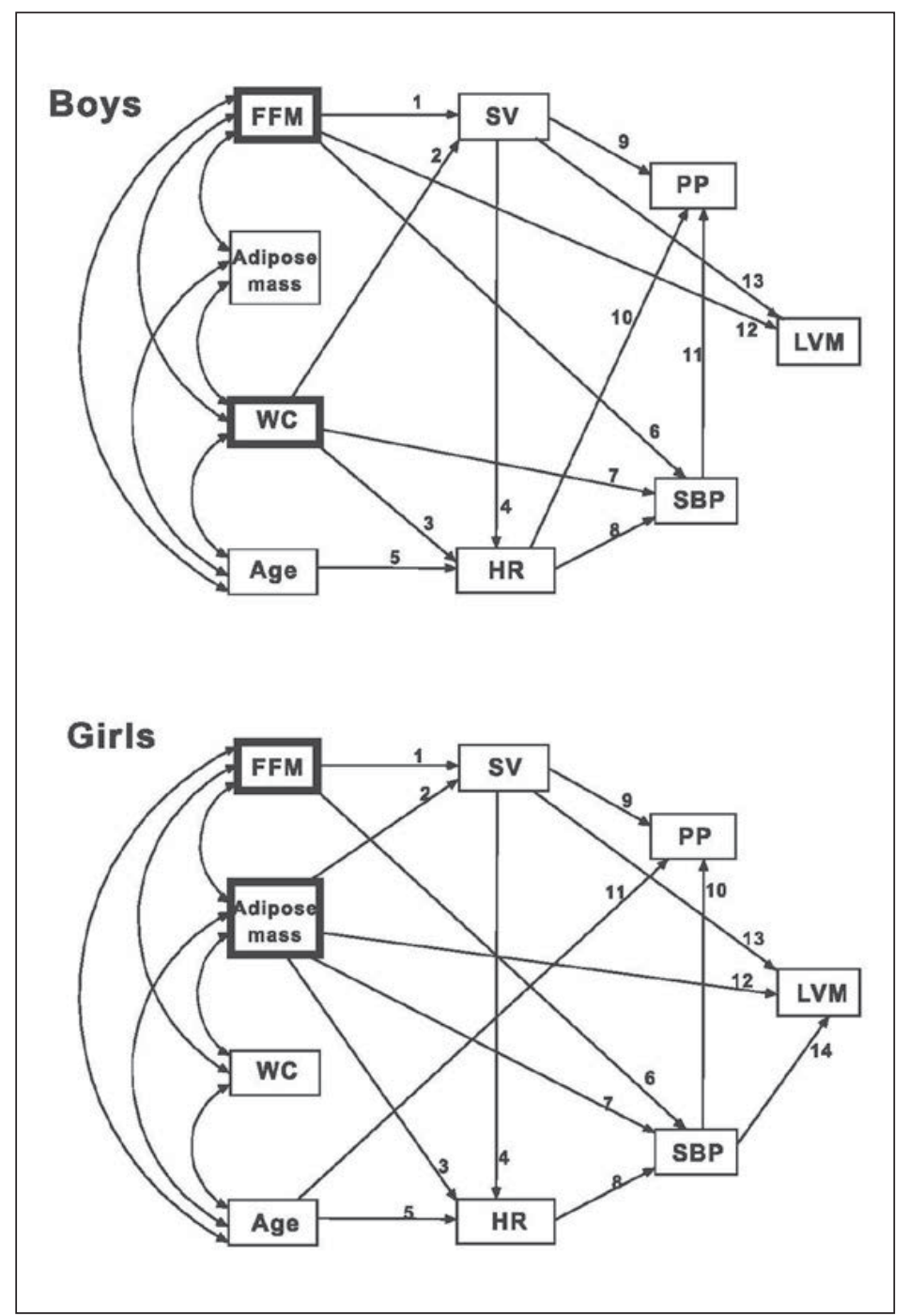

The direct effects of the variables are shown in table 3. In boys, SV was affected by FFM and WC. Adipose mass or age was not related to SV. HR correlated positively with WC but negatively with SV and age. FFM and adipose mass had no effect on HR. When CO was substituted for SV and HR, CO positively correlated with FFM and WC, but not with adipose mass. SBP was positively correlated with WC, FFM, and HR. On the other hand, SBP showed no association with adipose mass, SV, or age. SBP was a major determinant of PP. SV and HR had positive and negative effects on PP, respectively. None of the body composition variables nor age had a direct effect on PP. In the absence of SBP, PP showed positive relations to FFM (standardized estimate $=0.240 ; \mathrm{p}<0.001$ ) and WC (standardized estimate $=0.317 ; \mathrm{p}<0.001$ ), but not to adipose mass. LVM was determined primarily by FFM, followed by SV, but not by WC, adipose mass, HR, SBP, PP, or age.

In girls, FFM and adipose mass, but not WC or age, were related to SV. HR correlated positively with adipose mass and negatively with SV and age. FFM or WC had no effect on HR. When CO was substituted for SV and HR, CO was associated with FFM and adipose mass, but not with WC or age. SBP was positively correlated with adipose mass, FFM, and HR. SBP was not associated with WC, SV, or age. SBP was a main determinant of PP. PP correlated posi- 
Song et al.: Sex Differences in the Relation of Body Composition to Cardiovascular

Table 3. Direct effects of variables in boys and girls

\begin{tabular}{|c|c|c|c|c|c|c|c|c|}
\hline & \multicolumn{4}{|c|}{ Boys $(\mathrm{n}=397)$} & \multicolumn{4}{|c|}{ Girls ( $\mathrm{n}=279$ ) } \\
\hline & label $^{\mathrm{a}}$ & estimate & $\begin{array}{l}\text { standardized } \\
\text { estimate }\end{array}$ & p value & label $^{\mathrm{a}}$ & estimate & $\begin{array}{l}\text { standardized } \\
\text { estimate }\end{array}$ & $\mathrm{p}$ value \\
\hline $\mathrm{FFM} \rightarrow \mathrm{SV}$ & 1 & 0.733 & 0.471 & $<0.001$ & 1 & 0.864 & 0.311 & $<0.001$ \\
\hline $\mathrm{AM} \rightarrow \mathrm{SV}$ & - & - & - & - & 2 & 0.536 & 0.275 & $<0.001$ \\
\hline $\mathrm{WC} \rightarrow \mathrm{SV}$ & 2 & 0.22 & 0.179 & $<0.001$ & - & - & - & - \\
\hline Age $\rightarrow$ SV & - & - & - & - & - & - & - & - \\
\hline $\mathrm{FFM} \rightarrow \mathrm{HR}$ & - & - & - & - & - & - & - & - \\
\hline $\mathrm{AM} \rightarrow \mathrm{HR}$ & - & - & - & - & 3 & 0.323 & 0.142 & 0.037 \\
\hline $\mathrm{WC} \rightarrow \mathrm{HR}$ & 3 & 0.247 & 0.197 & $<0.001$ & - & - & - & - \\
\hline $\mathrm{SV} \rightarrow \mathrm{HR}$ & 4 & -0.325 & -0.317 & $<0.001$ & 4 & -0.248 & -0.212 & 0.001 \\
\hline Age $\rightarrow \mathrm{HR}$ & 5 & -1.907 & -0.136 & 0.006 & 5 & -1.568 & -0.118 & 0.049 \\
\hline $\mathrm{FFM} \rightarrow \mathrm{CO}^{\dagger}$ & & 0.046 & 0.359 & $<0.001$ & & 0.053 & 0.215 & $<0.001$ \\
\hline $\mathrm{AM} \rightarrow \mathrm{CO}^{\dagger}$ & & - & - & - & & 0.050 & 0.289 & $<0.001$ \\
\hline $\mathrm{WC} \rightarrow \mathrm{CO}^{\dagger}$ & & 0.027 & 0.262 & $<0.001$ & & - & - & - \\
\hline $\mathrm{Age} \rightarrow \mathrm{CO}^{\dagger}$ & & -0.162 & -0.142 & 0.007 & & - & - & - \\
\hline $\mathrm{FFM} \rightarrow \mathrm{SBP}$ & 6 & 0.332 & 0.252 & $<0.001$ & 6 & 0.32 & 0.128 & 0.045 \\
\hline $\mathrm{AM} \rightarrow \mathrm{SBP}$ & - & - & - & - & 7 & 0.655 & 0.374 & $<0.001$ \\
\hline $\mathrm{WC} \rightarrow \mathrm{SBP}$ & 7 & 0.348 & 0.335 & $<0.001$ & - & - & - & - \\
\hline $\mathrm{SV} \rightarrow \mathrm{SBP}$ & - & - & - & - & - & - & - & - \\
\hline $\mathrm{HR} \rightarrow \mathrm{SBP}$ & 8 & 0.12 & 0.145 & $<0.001$ & 8 & 0.157 & 0.204 & $<0.001$ \\
\hline Age $\rightarrow$ SBP & - & - & - & - & - & - & - & - \\
\hline $\mathrm{FFM} \rightarrow \mathrm{PP}$ & - & - & - & - & - & - & - & - \\
\hline $\mathrm{AM} \rightarrow \mathrm{PP}$ & - & - & - & - & - & - & - & - \\
\hline $\mathrm{WC} \rightarrow \mathrm{PP}$ & - & - & - & - & - & - & - & - \\
\hline $\mathrm{SV} \rightarrow \mathrm{PP}$ & 9 & 0.053 & 0.095 & 0.002 & 9 & 0.052 & 0.088 & 0.030 \\
\hline $\mathrm{HR} \rightarrow \mathrm{PP}$ & 10 & -0.051 & -0.093 & 0.002 & - & - & - & - \\
\hline $\mathrm{SBP} \rightarrow \mathrm{PP}$ & 11 & 0.522 & 0.794 & $<0.001$ & 10 & 0.489 & 0.738 & $<0.001$ \\
\hline Age $\rightarrow$ PP & - & - & - & - & 11 & -0.975 & -0.144 & $<0.001$ \\
\hline $\mathrm{FFM} \rightarrow \mathrm{LVM}$ & 12 & 1.845 & 0.508 & $<0.001$ & - & - & - & - \\
\hline $\mathrm{AM} \rightarrow \mathrm{LVM}$ & - & - & - & - & 12 & 1.752 & 0.467 & $<0.001$ \\
\hline $\mathrm{WC} \rightarrow \mathrm{LVM}$ & - & - & - & - & - & - & - & - \\
\hline $\mathrm{SV} \rightarrow \mathrm{LVM}$ & 13 & 0.487 & 0.208 & $<0.001$ & 13 & 0.369 & 0.192 & $<0.001$ \\
\hline $\mathrm{HR} \rightarrow \mathrm{LVM}$ & - & - & - & - & - & - & - & - \\
\hline $\mathrm{SBP} \rightarrow \mathrm{LVM}$ & - & - & - & - & 14 & 0.239 & 0.112 & 0.031 \\
\hline $\mathrm{PP} \rightarrow \mathrm{LVM}$ & - & - & - & - & - & - & - & - \\
\hline Age $\rightarrow$ LVM & - & - & - & - & - & - & - & - \\
\hline
\end{tabular}

FFM = Fat-free mass; $\mathrm{AM}=$ adipose mass; $\mathrm{WC}=$ waist circumference; $\mathrm{SV}=$ stroke volume; $\mathrm{HR}$ = heart rate; SBP = systolic blood pressure; $\mathrm{PP}=$ pulse pressure; LVM = left ventricular mass; estimate = path coefficient; standardized estimate $=$ standardized path coefficient. ${ }^{\text {a }}$ Numbers in path diagrams (fig. 1) indicating individual relations between variables. $-=$ Excluded correlation $(p \geq 0.05)$ based on stepwise multiple regression analysis which was conducted for the construction of the path diagram. ${ }^{\dagger}$ Substitution of CO for SV and HR

tively with SV and negatively with age. None of the body composition variables nor HR had any correlation with PP. In the absence of SBP, PP correlated with FFM (standardized estimate $=0.156 ; \mathrm{p}=0.023$ ) and adipose mass (standardized estimate $=0.293 ; \mathrm{p}<0.001$ ), but not with WC. LVM correlated with adipose mass, SV and SBP, but not with FFM, WC, HR, PP, or age.

In summary, the direct effect analyses showed that FFM was associated with SV, CO, and SBP in both sexes. Negative correlations of HR with SV and age were observed in boys as well as in girls. SBP was affected by HR, and PP correlated with SV and SBP in both sexes. Additionally, LVM positively correlated with SV in boys as well as in girls. 
Song et al.: Sex Differences in the Relation of Body Composition to Cardiovascular Parameters and Functions in Korean Adolescents: A School-Based Study

Table 4. Total effects of variables in boys and girls

\begin{tabular}{|c|c|c|c|c|}
\hline & \multicolumn{2}{|c|}{ Boys $(n=397)$} & \multicolumn{2}{|c|}{ Girls ( $n=279)$} \\
\hline & estimate & $\begin{array}{l}\text { standardized } \\
\text { estimate }\end{array}$ & estimate & $\begin{array}{l}\text { standardized } \\
\text { estimate }\end{array}$ \\
\hline $\mathrm{FFM} \rightarrow \mathrm{SV}$ & 0.733 & $0.471^{* * *}$ & 0.864 & $0.311^{* * *}$ \\
\hline $\mathrm{AM} \rightarrow \mathrm{SV}$ & 0 & 0 & 0.536 & $0.275^{* * *}$ \\
\hline $\mathrm{WC} \rightarrow \mathrm{SV}$ & 0.220 & $0.179^{* * *}$ & 0 & 0 \\
\hline $\mathrm{Age} \rightarrow \mathrm{SV}$ & 0 & 0 & 0 & 0 \\
\hline $\mathrm{FFM} \rightarrow \mathrm{HR}$ & -0.238 & $-0.149^{*}$ & -0.214 & -0.066 \\
\hline $\mathrm{AM} \rightarrow \mathrm{HR}$ & 0 & 0 & 0.190 & $0.083^{*}$ \\
\hline $\mathrm{WC} \rightarrow \mathrm{HR}$ & 0.176 & $0.140 *$ & 0 & 0 \\
\hline $\mathrm{SV} \rightarrow \mathrm{HR}$ & -0.325 & $-0.317^{* * *}$ & -0.248 & $-0.212^{* * *}$ \\
\hline Age $\rightarrow$ HR & -1.907 & $-0.136^{* *}$ & -1.568 & $-0.118^{*}$ \\
\hline $\mathrm{FFM} \rightarrow \mathrm{SBP}$ & 0.303 & $0.230^{* * *}$ & 0.287 & $0.115^{*}$ \\
\hline $\mathrm{AM} \rightarrow \mathrm{SBP}$ & 0 & 0 & 0.685 & $0.391^{* * *}$ \\
\hline $\mathrm{WC} \rightarrow \mathrm{SBP}$ & 0.370 & $0.355^{* * *}$ & 0 & 0 \\
\hline $\mathrm{SV} \rightarrow \mathrm{SBP}$ & -0.039 & -0.046 & -0.039 & -0.043 \\
\hline $\mathrm{HR} \rightarrow \mathrm{SBP}$ & 0.120 & $0.145^{* * *}$ & 0.157 & $0.204^{* * *}$ \\
\hline Age $\rightarrow$ SBP & -0.230 & -0.020 & -0.246 & -0.024 \\
\hline $\mathrm{FFM} \rightarrow \mathrm{PP}$ & 0.209 & $0.241^{* * *}$ & 0.287 & $0.115^{*}$ \\
\hline $\mathrm{AM} \rightarrow \mathrm{PP}$ & 0 & 0 & 0.363 & $0.313^{* * *}$ \\
\hline $\mathrm{WC} \rightarrow \mathrm{PP}$ & 0.196 & $0.286^{* * *}$ & 0 & 0 \\
\hline $\mathrm{SV} \rightarrow \mathrm{PP}$ & 0.049 & $0.088^{*}$ & 0.033 & 0.056 \\
\hline $\mathrm{HR} \rightarrow \mathrm{PP}$ & 0.012 & 0.022 & 0.077 & $0.151^{* *}$ \\
\hline $\mathrm{SBP} \rightarrow \mathrm{PP}$ & 0.522 & $0.794^{* * *}$ & 0.489 & $0.738^{* * *}$ \\
\hline Age $\rightarrow$ PP & -0.023 & -0.003 & -1.096 & $-0.161^{* *}$ \\
\hline $\mathrm{FFM} \rightarrow \mathrm{LVM}$ & 2.202 & $0.606^{* * *}$ & 0.387 & 0.073 \\
\hline $\mathrm{AM} \rightarrow \mathrm{LVM}$ & 0 & 0 & 2.113 & $0.564^{* * *}$ \\
\hline $\mathrm{WC} \rightarrow \mathrm{LVM}$ & 0.107 & 0.037 & 0 & 0 \\
\hline $\mathrm{SV} \rightarrow \mathrm{LVM}$ & 0.487 & $0.208^{* * *}$ & 0.360 & $0.187^{* *}$ \\
\hline $\mathrm{HR} \rightarrow \mathrm{LVM}$ & 0 & 0 & 0.037 & 0.023 \\
\hline $\mathrm{SBP} \rightarrow \mathrm{LVM}$ & 0 & 0 & 0.239 & $0.112^{*}$ \\
\hline $\mathrm{PP} \rightarrow \mathrm{LVM}$ & 0 & 0 & 0 & 0 \\
\hline Age $\rightarrow$ LVM & 0 & 0 & -0.059 & -0.003 \\
\hline
\end{tabular}

FFM = Fat-free mass; $\mathrm{AM}$ = adipose mass; $\mathrm{WC}=$ waist circumference; $\mathrm{SV}=$ stroke volume; $\mathrm{HR}=$ heart rate; $\mathrm{SBP}$ = systolic blood pressure; $\mathrm{PP}$ = pulse pressure; $\mathrm{LVM}=$ left ventricular mass. $0=$ No included direct or indirect correlation between the variables on the path diagram. ${ }^{*} \mathrm{p}<$ $0.05 ;{ }^{* *} \mathrm{p}<0.01$; $^{* *} \mathrm{p}<0.001$.

SV, CO, HR, and SBP correlated with WC only in boys and with adipose mass only in girls. PP was negatively influenced by HR only in boys and by age only in girls. LVM was associated with FFM only in boys and with adipose mass and SBP only in girls.

The total effects of the variables are shown in table 4. In boys, SV was affected by FFM and WC, but not by adipose mass or age. HR was related negatively to FFM, SV, and age and positively to WC, but not to adipose mass. SBP correlated with FFM, WC and HR, but not with adipose mass, SV, or age. PP had a relation to FFM, WC, SBP and SV, but not to adipose mass, HR, or age. LVM was influenced by FFM and SV, but not by WC, adipose mass, SBP, PP, HR, or age.

In girls, SV was correlated with FFM and adipose mass, but not with WC or age. HR was related negatively to SV and age and positively to adipose mass, but not to FFM or WC. SBP was influenced by FFM, adipose mass and HR, but not by WC, SV, or age. PP showed relations 
Song et al.: Sex Differences in the Relation of Body Composition to Cardiovascular

Table 5. Univariate correlates of body composition with cardiovascular functions adjusted for age in boys and girls

\begin{tabular}{|c|c|c|c|c|c|c|}
\hline & \multicolumn{3}{|c|}{ Boys $(n=397)$} & \multicolumn{3}{|c|}{ Girls $(n=279)$} \\
\hline & FFM & $\begin{array}{l}\text { adipose } \\
\text { mass }\end{array}$ & WC & FFM & $\begin{array}{l}\text { adipose } \\
\text { mass }\end{array}$ & WC \\
\hline Ejection fraction & -0.018 & 0.064 & 0.040 & 0.027 & 0.013 & 0.023 \\
\hline Fractional shortening & 0.012 & 0.069 & 0.051 & 0.044 & 0.014 & 0.030 \\
\hline E velocity & 0.015 & 0.039 & 0.057 & 0.085 & 0.044 & 0.072 \\
\hline A velocity & 0.086 & $0.174^{* * *}$ & $0.161^{* * *}$ & 0.074 & $0.170^{* *}$ & 0.097 \\
\hline $\mathrm{E} / \mathrm{A}$ ratio & -0.054 & $-0.114^{*}$ & $-0.104^{*}$ & -0.014 & $-0.117^{*}$ & -0.044 \\
\hline PWV & -0.059 & 0.087 & $0.109 *$ & -0.011 & $0.108^{*}$ & 0.045 \\
\hline
\end{tabular}

FFM = Fat-free mass; $\mathrm{WC}=$ waist circumference; $\mathrm{PWV}=$ pulse wave velocity.

${ }^{*} \mathrm{p}<0.05 ;{ }^{* *} \mathrm{p}<0.01 ;{ }^{* * *} \mathrm{p}<0.001$.

Table 6. Effect of overweight on cardiovascular parameters and functions in boys and girls

\begin{tabular}{|c|c|c|c|c|c|c|}
\hline & \multicolumn{3}{|l|}{ Boys $(\mathrm{n}=397)$} & \multicolumn{3}{|l|}{ Girls $(n=279)$} \\
\hline & $\begin{array}{l}\text { normal weight } \\
(\mathrm{n}=321)\end{array}$ & $\begin{array}{l}\text { overweight } \\
(n=76)\end{array}$ & $\mathrm{p}$ & $\begin{array}{l}\text { normal weight } \\
(\mathrm{n}=227)\end{array}$ & $\begin{array}{l}\text { overweight } \\
(n=52)\end{array}$ & $\mathrm{p}$ \\
\hline $\mathrm{SV}, \mathrm{ml}$ & $53.3 \pm 11.6$ & $62.6 \pm 11.7$ & $<0.001$ & $48.1 \pm 9.5$ & $56.3 \pm 11.4$ & $<0.001$ \\
\hline $\mathrm{SV} / \mathrm{BSA}, \mathrm{ml} / \mathrm{m}^{2}$ & $34.3 \pm 6.4$ & $33.6 \pm 5.5$ & NS & $33.1 \pm 5.9$ & $34.2 \pm 6.2$ & NS \\
\hline $\mathrm{CO}, \mathrm{l} / \mathrm{min}$ & $3.9 \pm 0.9$ & $4.7 \pm 1.0$ & $<0.001$ & $3.7 \pm 0.8$ & $4.3 \pm 1.0$ & $<0.001$ \\
\hline $\mathrm{CO} / \mathrm{BSA}, \mathrm{l} / \mathrm{min} / \mathrm{m}^{2}$ & $2.5 \pm 0.5$ & $2.5 \pm 0.5$ & NS & $2.5 \pm 0.5$ & $2.6 \pm 0.5$ & NS \\
\hline SBP, mm Hg & $114.2 \pm 9.1$ & $122.8 \pm 10.9$ & $<0.001$ & $107.6 \pm 8.3$ & $116.8 \pm 8.1$ & $<0.001$ \\
\hline $\mathrm{DBP}, \mathrm{mm} \mathrm{Hg}$ & $60.8 \pm 5.9$ & $64.7 \pm 6.7$ & $<0.001$ & $60.1 \pm 5.9$ & $64.2 \pm 5.3$ & $<0.001$ \\
\hline $\mathrm{PP}, \mathrm{mm} \mathrm{Hg}$ & $53.4 \pm 6.3$ & $58.1 \pm 6.8$ & $<0.001$ & $47.5 \pm 5.8$ & $52.5 \pm 5.2$ & $<0.001$ \\
\hline LV mass, g & $113.5 \pm 24.9$ & $136.2 \pm 31.2$ & $<0.001$ & $102.4 \pm 18.6$ & $125.9 \pm 26.6$ & $<0.001$ \\
\hline LV mass/BSA, g/m² & $73.0 \pm 13.4$ & $72.9 \pm 14.6$ & NS & $70.5 \pm 11.1$ & $71.6 \pm 14.4$ & NS \\
\hline Ejection fraction, \% & $68.1 \pm 4.1$ & $68.6 \pm 4.3$ & NS & $67.0 \pm 6.0$ & $67.0 \pm 6.2$ & NS \\
\hline Fractional shortening, \% & $39.0 \pm 3.6$ & $39.7 \pm 3.7$ & NS & $37.1 \pm 5.0$ & $37.0 \pm 4.7$ & NS \\
\hline E velocity, $\mathrm{cm} / \mathrm{s}$ & $105.6 \pm 17.3$ & $106.4 \pm 14.4$ & NS & $100.5 \pm 13.9$ & $100.9 \pm 15.1$ & NS \\
\hline A velocity, $\mathrm{cm} / \mathrm{s}$ & $52.9 \pm 11.0$ & $54.9 \pm 11.6$ & NS & $53.1 \pm 11.0$ & $52.9 \pm 10.5$ & NS \\
\hline E/A ratio & $2.09 \pm 0.62$ & $2.02 \pm 0.51$ & NS & $1.97 \pm 0.49$ & $1.97 \pm 0.45$ & NS \\
\hline $\mathrm{PWV}, \mathrm{cm} / \mathrm{s}$ & $934.9 \pm 102.7$ & $957.9 \pm 110.2$ & 0.049 & $940.5 \pm 93.3$ & $955.9 \pm 82.1$ & NS \\
\hline
\end{tabular}

$\mathrm{BSA}=$ Body surface area; $\mathrm{SV}=$ stroke volume; $\mathrm{CO}=$ cardiac output; $\mathrm{SBP}=$ systolic blood pressure; $\mathrm{DBP}=$ diastolic blood pressure; $\mathrm{PP}=$ pulse pressure; $\mathrm{PWV}=$ pulse wave velocity; $\mathrm{NS}=$ nonsignificant. Data are means \pm SD.

to SBP, FFM, adipose mass, HR and age, but not to WC or SV. LVM was affected by adipose mass, SBP and SV, but not by FFM, WC, HR, PP, or age.

In summary, SV, SBP, and PP correlated with FFM in both sexes, with WC only in boys, and with adipose mass only in girls. HR was affected by FFM and WC in boys and by adipose mass in girls. LVM turned out to be associated with FFM in boys and with adipose mass in girls.

\section{Correlations of Body Composition with Cardiovascular Function}

In age-adjusted analyses of the relations between body composition and cardiovascular function, FFM, adipose mass, and WC had no effect on ejection fraction, fractional shortening, or E velocity in boys or girls (table 5). The A velocity was positively related to adipose mass 
Song et al.: Sex Differences in the Relation of Body Composition to Cardiovascular

Parameters and Functions in Korean Adolescents: A School-Based Study

and WC, but not to FFM, in boys. In girls, the A velocity was associated with adipose mass, but not with FFM or WC. Adipose mass, but not FFM, had a negative correlation with the E/A ratio in both boys and girls. WC correlated negatively with the E/A ratio in boys, but not in girls. No relation was observed between the E/A ratio and LVM in boys $(\beta=0.041 ; p=0.412)$ or girls $(\beta=0.028 ; p=0.644)$. PWV correlated with WC only in boys and with adipose mass only in girls. There was no relation between PWV and FFM in both sexes.

\section{Correlations of Overweight with Cardiovascular Parameters and Functions}

Overweight participants had higher SV, CO, and LVM than those of normal weight in both boys and girls, whereas normalization for body surface area eliminated these differences between the normal-weight and overweight groups (table 6). SBP, diastolic blood pressure (DBP), and PP were higher in the overweight than in the normal-weight group in both sexes. There were no differences in ejection fraction, fractional shortening, E velocity, A velocity, or E/A ratio between normal-weight and overweight participants in either sex. Overweight participants had a higher PWV than normal-weight participants in boys, but not in girls.

\section{Discussion}

In the present study, we investigated the relations between body composition and cardiovascular system parameters in adolescents. We found that cardiovascular parameters and functions correlated with body composition variables (FFM, adipose mass, WC) differently in boys and girls.

\section{Correlations of Body Composition with Cardiovascular Parameters}

Without adjustment for other body composition variables, all body composition variables (FFM, adipose mass, and WC) were well correlated with SV, CO, SBP, PP, and LVM. However, these positive correlations between individual body composition variables and cardiovascular parameters might be confounded by the indirect effects of other body composition variables, since FFM, adipose mass, and WC may be correlated with each other.

To determine the true independent effects of body composition variables on cardiovascular parameters, we performed a path analysis which provides the full range of relations between variables. The main findings of the path analysis are as follows: i) SV and SBP were associated with FFM and WC in boys and with FFM and adipose mass in girls in direct- and total-effects analysis. ii) HR had a correlation with WC in boys and with adipose mass in girls in direct- and total-effects analysis. In total-effects analysis in boys, FFM had a negative correlation with HR, while it did not directly affect HR. iii) PP was not directly influenced by any of the body composition parameters in either sex. However, in total-effects analysis, PP correlated with FFM and WC in boys and with FFM and adipose mass in girls. iv) LVM was affected by FFM in boys and by adipose mass in girls in direct- and total-effects analysis. WC did not correlate with LVM in either sex in direct- or total-effects analysis.

\section{Correlations of Body Composition with Stroke Volume and Cardiac Output}

FFM consists of organ cell mass and non-fatty tissues, including tendons, ligaments and bones, which generate the majority of metabolic activity in the body and govern its total oxygen demand. Up to $99 \%$ of the body metabolism takes place in body cell mass [23]. Since CO is closely related to metabolism, FFM is a major determinant of the required $\mathrm{CO}$ and SV with a given HR.

In addition, adipose tissue is related to increased blood flow. To prevent hypoxic damage of adipose tissue and to transport metabolic factors, including adipocyte progenitors, increases in circulating blood volume in adipose tissue are required to maintain adipose mass 
Song et al:: Sex Differences in the Relation of Body Composition to Cardiovascular

Parameters and Functions in Korean Adolescents: A School-Based Study

[24]. During puberty, sex hormones act differently towards adiposity in boys and girls; the total adipose mass decreases in boys and increases in girls [25]. Girls expand peripheral (subcutaneous and gluteal) fat rather than central (intra-abdominal) fat [26], whereas boys accumulate fat primarily in the abdominal area [27]. Thus, it may be that blood flow parameters (SV and CO) are associated with total fat in girls and central fat in boys.

\section{Correlations of Body Composition with Blood Pressure}

BP (SBP and PP) is determined by blood flow and vascular impedance, which is influenced by vascular stiffness and contraction. As mentioned above, blood flow is associated with FFM in both boys and girls, with adipose mass in girls, and with WC in boys. Thus, these effects of body composition on blood flow patterns contribute, in part, to the determination of BP.

Adipose tissue is known to play important roles in vascular impedance (vascular stiffness and contraction) [28]. Adipose tissue releases free fatty acids and thereby induces the accumulation of free fatty acids in multiple organs, contributing to insulin resistance [29] and increased adrenergic activity [30] and resulting in increased vascular tone [31]. During puberty, sex hormones react differently with adipose tissue in girls and boys. In boys, the male sex hormone testosterone induces lipolysis of general body fat and accumulation of central fat [32]. General body fat is used as a fuel in protein synthesis and muscle fiber growth, whereas central fat has a deleterious effect on vascular walls. In girls, the general fat mass increases because of endocrine factors that counteract growth hormone effects, including regionalized expression of estradiol receptors [27], possibly resulting in increased vascular stiffness. The female sex hormone estrogen stimulates lipolysis in abdominal fat deposits and promotes the use of lipids as a fuel by muscles instead of accumulating free fatty acids [33]; the net effect is a reduction in central adiposity [34]. The direct effects of body composition on BP and PWV analyzed in this study as well as in previous studies [35] are well consistent with this theory.

\section{Correlations of Body Composition with Left Ventricular Mass}

Previous studies investigating the correlations between LVM and mechanical factors (volume load and pressure load) showed that LVM correlated more closely with SV than with $\mathrm{BP}[36,37]$, as observed in the present study. FFM is related to LVM, probably because of the effects of FFM on hemodynamic factors (blood flow and pressure) [38]. Alternatively, genetic and hormonal influences that affect FFM growth may also directly affect the heart, resulting in cardiac hypertrophy. Accordingly, the expansion rate of FFM may be an indicator of these genetic and hormonal influences on the heart [39]. During puberty, FFM rapidly expands in boys, but not in girls [25]. Thus, it can be speculated that the factors that induce the increases in both FFM and LVM are more active in boys than in girls. Therefore, FFM correlates with LVM better in boys than in girls, as seen in our data.

Adipose tissue is also a correlating factor of LVM. A previous study reported that fat tissue might mediate LVM increases by insulin resistance [40]. Insulin may influence cardiac geometry by its growth-stimulating, sodium retention, and other neuroendocrine effects [7]. Adipose tissue may induce circulating angiotensin II, which promotes myocardial tissue growth and influences aldosterone, which may mediate myocardial fibrosis [41]. As mentioned earlier, fat from adipose tissue is metabolized as fuel in boys and increases in girls during puberty [25]. Thus, adipose mass may correlate with LVM only in girls, as we observed.

\section{Correlations of Body Composition with Cardiac Function}

Most studies using echocardiography, including ours, have shown that adiposity can affect LV diastolic function, but not systolic function [42]. These findings suggest that LV 
Song et al.: Sex Differences in the Relation of Body Composition to Cardiovascular

Parameters and Functions in Korean Adolescents: A School-Based Study

systolic function, but not diastolic function, is well preserved in the presence of the metabolic impact of fat tissue.

Cardiac diastolic function is known to be related to cardiac geometry and composition [42-44]. As noted above, adipose tissue causes insulin resistance and renin-angiotensin-aldosterone and sympathoadrenal system activation $[42,45,46]$, which promotes cardiac hypertrophy and fibrosis and may thereby induce LV diastolic dysfunction. Consistent with this, our results showed that adipose mass correlated with the A velocity and the E/A ratio in both boys and girls. Probably because of the effects of estrogen on visceral fat, WC was associated with the A velocity and the E/A ratio only in boys. According to our data, simple LV hypertrophy seems not to affect diastolic function during adolescence because the A velocity and the E/A ratio showed no relation with LVM in boys or girls.

\section{Correlations of Overweight with Cardiovascular Parameters and Functions}

When comparing normal-weight and overweight groups, blood flow (SV and CO), BP (SBP, DBP, and PP), and LVM were higher in the overweight group in boys as well as in girls. The overweight group was determined according to the BMI percentile. These results show that the sum of body composition variables is well correlated with blood flow, BP, and LVM in both sexes, as inferred from the analyses of the individual body composition effects. When normalized with body surface area, overweight did not increase blood flow or LVM. Interestingly, it can be speculated that peripheral vascular resistance is greater in the overweight group in both sexes as evidenced by the higher DBP in the overweight participants, suggesting that there are no sex differences in this parameter despite the differences in the location of the additional fat mass.

Among the cardiovascular function parameters (ejection fraction, fractional shortening, E velocity, A velocity, E/A ratio and PWV), overweight was associated only with PWV in boys.

One of the limitations of our study is that we did not measure the Tanner stage or sex hormones, which might have affected the accuracy of the analyses of pubertal effects. Investigation of lipid profiles, cytokines, insulin resistance, sympathetic nervous system activity, renin-angiotensin-aldosterone system activity, eating behavior, and physical activity could have provided additional information about underlying mechanisms. We did not measure hemoglobin concentrations, which might have affected the hemodynamic correlations. Measurement errors in the BIA may have attributed a certain portion of FFM to adipose mass, thereby overestimating the effects of adipose mass on cardiovascular parameters and functions. In order to clarify the association of body composition with the cardiovascular system during adolescence, further studies should include direct measurements of abdominal visceral fat in addition to the above mentioned measurements.

\section{Acknowledgments}

This work was supported by research funds from the Korea Heart Foundation (KHF) (2007) and the Inje University College of Medicine.

\section{Disclosure Statement}

The authors have disclosed no conflicts of interest. 
Song et al.: Sex Differences in the Relation of Body Composition to Cardiovascular

Parameters and Functions in Korean Adolescents: A School-Based Study

\section{References}

1 Zhu H, Yan W, Ge D, Treiber FA, Harshfield GA, Kapuku G, Snieder H, Dong Y: Relationships of cardiovascular phenotypes with healthy weight, at risk of overweight, and overweight in US youths. Pediatrics 2008;121: 115-122.

-2 Bibbins-Domingo K, Coxson P, Pletcher MJ, Lightwood J, Goldman L: Adolescent overweight and future adult coronary heart disease. N Engl J Med 2007;357:2371-2379.

3 de Divitiis O, Fazio S, Petitto M, Maddalena G, Contaldo F, Mancini M: Obesity and cardiac function. Circulation 1981;64:477-482.

-4 Lauer MS, Anderson KM, Levy D: Separate and joint influences of obesity and mild hypertension on left ventricular mass and geometry: the Framingham Heart Study. J Am Coll Cardiol 1992;19:130-134.

-5 Messerli FH, Sundgaard-Riise K, Reisin ED, Dreslinski GR, Ventura HO, Oigman W, Frohlich ED, Dunn FG: Dimorphic cardiac adaptation to obesity and arterial hypertension. Ann Intern Med 1983;99:757-761.

6 Alexander JK: The cardiomyopathy of obesity. Prog Cardiovasc Dis 1985;27:325-334.

7 Poirier P, Giles TD, Bray GA, Hong Y, Stern JS, Pi-Sunyer FX, Eckel RH; American Heart Association; Obesity Committee of the Council on Nutrition, Physical Activity, and Metabolism: Obesity and cardiovascular disease: pathophysiology, evaluation, and effect of weight loss: an update of the 1997 American Heart Association Scientific Statement on Obesity and Heart Disease from the Obesity Committee of the Council on Nutrition, Physical Activity, and Metabolism. Circulation 2006;113:898-918.

-8 Yusuf S, Hawken S, Ounpuu S, Bautista L, Franzosi MG, Commerford P, Lang CC, Rumboldt Z, Onen CL, Lisheng L, Tanomsup S, Wangai P Jr, Razak F, Sharma AM, Anand SS; INTERHEART Study Investigators: Obesity and the risk of myocardial infarction in 27,000 participants from 52 countries: a case-control study. Lancet 2005; 366:1640-1649.

-9 Peiris AN, Sothmann MS, Hoffmann RG, Hennes MI, Wilson CR, Gustafson AB, Kissebah AH: Adiposity, fat distribution, and cardiovascular risk. Ann Intern Med 1989;110:867-872.

10 Hayashi T, Boyko EJ, Leonetti DL, McNeely MJ, Newell-Morris L, Kahn SE, Fujimoto WY: Visceral adiposity is an independent predictor of incident hypertension in Japanese Americans. Ann Intern Med 2004;140:992-1000.

11 Forbes GB, Welle SL: Lean body mass in obesity. Int J Obes 1983; 7:99-107.

12 Collis T, Devereux RB, Roman MJ, de Simone G, Yeh J, Howard BV, Fabsitz RR, Welty TK: Relations of stroke volume and cardiac output to body composition: the Strong Heart Study. Circulation 2001;103:820-825.

13 Whalley GA, Gamble GD, Doughty RN, Culpan A, Plank L, MacMahon S, Sharpe N: Left ventricular mass correlates with fat-free mass but not fat mass in adults. J Hypertens 1999;17:569-574.

14 Syme C, Abrahamowicz M, Leonard GT, Perron M, Richer L, Veillette S, Xiao Y, Gaudet D, Paus T, Pausova Z: Sex differences in blood pressure and its relationship to body composition and metabolism in adolescence. Arch Pediatr Adolesc Med 2009;163:818-825.

15 Cha K, Chertow GM, Gonzalez J, Lazarus JM, Wilmore DW: Multifrequency bioelectrical impedance estimates the distribution of body water. J Appl Physiol 1995;79:1316-1319.

16 Lang RM, Bierig M, Devereux RB, Flachskampf FA, Foster E, Pellikka PA, Picard MH, Roman MJ, Seward J, Shanewise JS, Solomon SD, Spencer KT, Sutton MS, Stewart WJ; Chamber Quantification Writing Group; American Society of Echocardiography's Guidelines and Standards Committee; European Association of Echocardiography: Recommendations for chamber quantification: a report from the American Society of Echocardiography's Guidelines and Standards Committee and the Chamber Quantification Writing Group, developed in conjunction with the European Association of Echocardiography, a branch of the European Society of Cardiology. J Am Soc Echocardiogr 2005;18:1440-1463.

17 Mathews L, Singh RK: Cardiac output monitoring. Ann Card Anaesth 2008;11:56-68.

-18 Devereux RB, Alonso DR, Lutas EM, Gottlieb GJ, Campo E, Sachs I, Reichek N: Echocardiographic assessment of left ventricular hypertrophy: comparison to necropsy findings. Am J Cardiol 1986;57:450-458.

19 Mercier JC, DiSessa TG, Jarmakani JM, Nakanishi T, Hiraishi S, Isabel-Jones J, Friedman WF: Two-dimensional echocardiographic assessment of left ventricular volumes and ejection fraction in children. Circulation 1982; 65:962-969.

20 Munakata M, Ito N, Nunokawa T, Yoshinaga K: Utility of automated brachial ankle pulse wave velocity measurements in hypertensive patients. Am J Hypertens 2003;16:653-657.

-21 Streiner DL: Finding our way: an introduction to path analysis. Can J Psychiatry 2005;50;115-122.

22 Korea Centers for Disease Control and Prevention TKPS, The Committee for the Development of Growth Standard for Korean Children and Adolescents: 2007 Korean children and adolescents growth standard (commentary for the development of 2007 growth chart). Government report online (in Korean). http://cdc. go. kr/CDC/info/CdcKrInfo 0201.jsp?menuIds=HOME001-MNU1155-MNU1083-MNU1375MNU0025\&fid=28\&q_type $=$ title\&q_value $=\% E C \% 84 \% B 1 \% E C \% 9 E \% A 5 \% E B \% 8 F \% 84 \% E D \% 91 \% 9 C \&$ cid $=1235$ \&pageNum = (last accessed March 27, 2014).

23 Moore FD: Energy and the maintenance of the body cell mass. JPEN J Parenter Enteral Nutr 1980;4:228-260.

24 Rutkowski JM, Davis KE, Scherer PE: Mechanisms of obesity and related pathologies: the macro- and microcirculation of adipose tissue. FEBS J 2009;276:5738-5746.

25 Moran A, Jacobs DR Jr, Steinberger J, Steffen LM, Pankow JS, Hong CP, Sinaiko AR: Changes in insulin resistance and cardiovascular risk during adolescence: establishment of differential risk in males and females. Circulation 2008;117:2361-2368. 
Song et al.: Sex Differences in the Relation of Body Composition to Cardiovascular Parameters and Functions in Korean Adolescents: A School-Based Study

26 Kissebah AH, Krakower GR: Regional adiposity and morbidity. Physiol Rev 1994;74:761-811.

27 Loomba-Albrecht LA, Styne DM: Effect of puberty on body composition. Curr Opin Endocrinol Diabetes Obes 2009;16:10-15.

28 Lee JW, Lee HR, Shim JY, Im JA, Kim SH, Choi H, Lee DC: Viscerally obese women with normal body weight have greater brachial-ankle pulse wave velocity than nonviscerally obese women with excessive body weight. Clin Endocrinol (Oxf) 2007;66:572-578.

-29 Björntorp P: Body fat distribution, insulin resistance, and metabolic diseases. Nutrition 1997;13:795-803.

-30 Strain GW, Zumoff B, Strain JJ, Levin J, Fukushima DK: Cortisol production in obesity. Metabolism 1980;29: 980-985.

31 Scherrer U, Sartori C: Insulin as a vascular and sympathoexcitatory hormone: implications for blood pressure regulation, insulin sensitivity, and cardiovascular morbidity. Circulation 1997;96:4104-4113.

32 Veldhuis JD, Roemmich JN, Richmond EJ, Rogol AD, Lovejoy JC, Sheffield-Moore M: Endocrine control of body composition in infancy, childhood, and puberty. Endocr Rev 2005;26:114-146.

-33 D’Eon TM, Souza SC, Aronovitz M, Obin MS, Fried SK, Greenberg AS: Estrogen regulation of adiposity and fuel partitioning. Evidence of genomic and non-genomic regulation of lipogenic and oxidative pathways. J Biol Chem 2005;280:35983-35991.

34 Perrone G, Liu Y, Capri O, Critelli C, Barillaro F, Galoppi P, Zichella L: Evaluation of the body composition and fat distribution in long-term users of hormone replacement therapy. Gynecol Obstet Invest 1999;48:52-55.

-35 He Q, Horlick M, Fedun B, Wang J, Pierson RN Jr, Heshka S, Gallagher D: Trunk fat and blood pressure in children through puberty. Circulation 2002;105:1093-1098.

-36 Jones EC, Devereux RB, O'Grady MJ, Schwartz JE, Liu JE, Pickering TG, Roman MJ: Relation of hemodynamic volume load to arterial and cardiac size. J Am Coll Cardiol 1997;29:1303-1310.

-37 de Simone G, Devereux RB, Daniels SR, Mureddu G, Roman MJ, Kimball TR: Stroke volume and cardiac output in normotensive children and adults. Assessment of relations with body size and impact of overweight. Circulation 1997; 95:1837-1843.

38 Devereux RB, Roman MJ, de Simone G, O’Grady MJ, Paranicas M, Yeh JL, Fabsitz RR, Howard BV: Relations of left ventricular mass to demographic and hemodynamic variables in American Indians: the Strong Heart Study. Circulation 1997; 96:1416-1423.

-39 Bella JN, Devereux RB, Roman MJ, O'Grady MJ, Welty TK, Lee ET, Fabsitz RR, Howard BV: Relations of left ventricular mass to fat-free and adipose body mass: the Strong Heart Study. The Strong Heart Study Investigators. Circulation 1998;98:2538-2544.

$\checkmark 40$ Karason K, Sjöström L, Wallentin I, Peltonen M: Impact of blood pressure and insulin on the relationship between body fat and left ventricular structure. Eur Heart J 2003;24:1500-1505.

-41 Engeli S, Negrel R, Sharma AM: Physiology and pathophysiology of the adipose tissue renin-angiotensin system. Hypertension 2000;35:1270-1277.

-42 Gates PE, Gentile CL, Seals DR, Christou DD: Adiposity contributes to differences in left ventricular structure and diastolic function with age in healthy men. J Clin Endocrinol Metab 2003;88:4884-4890.

43 Peterson LR, Waggoner AD, Schechtman KB, Meyer T, Gropler RJ, Barzilai B, Dávila-Román VG: Alterations in left ventricular structure and function in young healthy obese women: assessment by echocardiography and tissue Doppler imaging. J Am Coll Cardiol 2004;43:1399-1404.

-44 Powell BD, Redfield MM, Bybee KA, Freeman WK, Rihal CS: Association of obesity with left ventricular remodeling and diastolic dysfunction in patients without coronary artery disease. Am J Cardiol 2006;98:116-120.

-45 Weise M, Eisenhofer G, Merke DP: Pubertal and gender-related changes in the sympathoadrenal system in healthy children. J Clin Endocrinol Metab 2002;87:5038-5043.

-46 Quilliot D, Alla F, Böhme P, Bruntz JF, Hammadi M, Dousset B, Ziegler 0, Zannad F: Myocardial collagen turnover in normotensive obese patients: relation to insulin resistance. Int J Obes 2005;29:1321-1328. 